\title{
DEMAND AND SUPPLY PROJECTION OF CEREALS: CONSEQUENCE TO FOOD SECURITY IN INDIA AND NIGERIA
}

\section{Isah Musa Ahmad ${ }^{1}$}

\section{Sadiq M.S. ${ }^{2}$}

\section{ARTICLE INFO}

\section{Article history:}

Received 13 Feb 2021

Accepted 9 Nov 2021

\section{JEL classification:}

\section{Keywords:}

Demand

Supply

Food security

Cereals

\begin{abstract}
The paper presents demand and supply projection of major cereals for the year 2030,2040 and 2050 for both India and Nigeria and the implication on food security challenge. The demand projections were computed using simple growth rate model under the assumptions of 6, 7 and 8 per cent GDP growth rate representing low-, moderate- and high-income growth. Results indicated that in both India and Nigeria increase in income do not cause any significant increase in the demand for cereals. It is concluded that India would be a self-sufficient in rice, wheat and maize with deficit in sorghum for the years 2030, 2040 and 2050 respectively. On the other hand, Nigeria would be plunging into a huge deficit in rice, wheat and a marginal surplus in maize and sorghum for the year 2030 with deteriorating deficits in the years 2040 and 2050 in rice, wheat, maize and sorghum respectively. In the study period, there would be surplus of cereals in the India with exception of sorghum; these prospects need to be strengthened and expand to sorghum through vigorous expansionary production programs as well ensure more availability, accessibility and affordability of cereal among poor families of India. For Nigeria to meet the future food requirements, the country shall have to either increase agricultural production, or depend on imports. As such, the paper suggests that the policy focus needs to be lunched, towards massive production, productivity enhancement in agriculture, through public investment in irrigation, credit facilities, research and extension.
\end{abstract}

\footnotetext{
${ }^{1}$ National Agricultural Extension and Research Liaison Services, ABU, Zaria, Nigeria

2 Department of Agricultural Economics and Extension, FUD, Dutse, Nigeria, $\underline{\text { adiqsanusi30@gmail.com, }}$ DOI: $10.53839 /$ aifd. 944053
} 


\section{INTRODUCTION}

Food security exists when all people have physical and economic access to enough, safe, and nutritious food to meet their dietary needs and preferences for an active and healthy life at all times (World Food Summit, 1996). Food security and poverty are considered to be a developing country phenomenon that is a relevant and current priority in countries such as India and Nigeria (Buhi, 2009; Holben. 2010). According to Kirit (1998), food security refers to a government's ability to provide enough food to all of its citizens in terms of quantity, accessibility, and nutritional value.

"Moreover, food should be provided to everyone as a matter of right, without causing the poor any humiliation." Many international organizations have designated it as a human right, describing it as one of the most basic human needs that every government should strive to meet.

Despite its rapid economic development, India stands out as one of the most food insecure countries in the world. "No country in the world comes close to India in terms of the absolute number of people living in chronic hunger," according to the FAO's 2006 Report on the State of Food Insecurity in the World (Madhura, 2010). Currently, 230 million people in rural areas are malnourished; $40 \%$ of children under the age of three are underweight, and 45 percent have stunted growth; anemia has increased to a rate of 79 percent in children under the age of five, and 56 percent in young women (Ghakur, 2011).

Two-thirds of Nigeria's population lives in poverty, and household food security is insufficient. Nigeria is afflicted by both income and food poverty, with a lack of access to resources to support rural development being one of the roots causes (FGN/WHO 2004). Nigeria, as Atinmo (1999) correctly observed, is one of the food-deficit countries in sub-Saharan Africa, despite being arguably more productive than the others. It has also avoided major disasters that could have resulted in famine, mass hunger, and, as a result, a food crisis.
For thousands of years, cereal grains have been considered the primary component of human diets and have played a significant role in shaping human civilization. Rice, wheat, and maize, as well as sorghum and millets to a lesser extent, are important staples for billions of people around the world. Cereal grain consumption accounts for more than half of the world's daily caloric intake. The majority of grain used for human consumption is milled to remove the bran (peri-carp) and germ, primarily to meet consumer sensory expectations.

For the vast majority of the world's population, cereal grains are the single most important source of calories. In comparison to the developed world, developing countries rely more on cereal grains for their nutritional needs. Cereals account for nearly $60 \%$ of calories consumed in developing countries, with values exceeding $80 \%$ in the poorest countries. In contrast, cereals provide approximately $30 \%$ of calories in the developed world. Even in these more affluent societies, where direct cereal consumption is less common, cereals remain the most important food commodity, as they provide the majority of nutrients for the livestock that are a major part of the diet in these areas (Anon, 2003).

India and Nigeria are two of the most important cereal producing and consuming countries in Asia and Africa, but they face food insecurity because cereal cultivation is dominated by smallholders with low output. The cereal crop makes a significant contribution to a country's food security level (Isa et al., 2015).

In a country like Nigeria, with such a large rural and agrarian population, food security and cereal productivity are inextricably linked. As a result, factors affecting the cereals industry have a direct impact on food security, as cereals are comparatively cheaper than any other form of diet for the majority of the poor population (FAO, 2014).

India's food grain production increased from 82 million tons in 1960-61 to around 203 million tons in 1998-99, according to Gokal et al. (2001). During this time, it has grown at a rate of 2.68 percent per 
year, which is a significant achievement. From a near-famine situation in the mid-1960s, India has now become self-sufficient in food grain production.

\section{Structure of India and Nigeria Agriculture}

Agriculture has always been, and will continue to be, the backbone of the Indian economy. It supports nearly $17 \%$ of the world's population on 2.3 percent of the world's land and 4.2 percent of the world's water resources (Anand et al., 2016). The country's economy has been on a stronger growth trajectory thanks to economic changes implemented in the early 1990s.

The country is trying to figure out how to feed its rapidly expanding population. On the one hand, it is dealing with diminishing productivity and, on the other, liberalization-related issues. In such a situation, the only option to make ends meet is to make use of accessible natural resources and existing infrastructure (Anand et al., 2016). The call of the day is to manage existing infrastructure in a way that is in harmony with natural systems.

Food security has long been a contentious subject in India, which has the world's highest concentration of underprivileged people. The Government of India has launched a number of production (supply), distribution, and consumption (demand) programs across the country after nearly achieving self-sufficiency in staple foods (Kumar et al., 2016). According to India's predicted food requirement and total production of major crops, food grain demand will be 240 MT by 2020 and 300 MT by 2025 to keep up with current population growth and consumption patterns. To achieve these demand forecasts, annual agricultural growth needs be kept at 6.7 percent.

Nigeria had a total food supply of 2,572 kcal per capita per day in 2018. Despite the fact that Nigeria's total food supply has fluctuated significantly in recent years, it has tended to rise from 1969 to 2018, reaching 2,572 kcal per capita per day in 2018 (Hussain and Sulaimon, 2018).
Agriculture generated 22.35 percent of the overall Gross Domestic Product between January and March 2021. Over 70\% (Anonymous, 2021a) of Nigerians work in agriculture, primarily for subsistence purposes.

Despite its importance to the economy, Nigeria's agriculture sector suffers numerous obstacles that have a negative influence on productivity. Poor land tenure, low irrigated farming, climate change, and land degradation are only a few of them. Low technology, high production costs, and inadequate input distribution are among the others, as are limited financing, large post-harvest losses, and poor market access. These issues have hindered agricultural output, impacting the sector's contribution to the country's GDP, as well as increased food imports as a result of population growth, resulting in diminishing food sufficiency levels. For example, Nigeria's total agricultural imports were N3.35 trillion between 2016 and 2019 (Anonymous, 2021b), four times larger than the N803 billion in agricultural exports during the same period.

Agriculture Promotion Policy (APP), Nigeria-Africa Trade and Investment Promotion Programme, Presidential Economic Diversification Initiative, Economic and Export Promotion Incentives, and the Zero Reject Initiative, Reducing Emissions from Deforestation and Forest Degradation (REDD+); Nigeria Erosion and Watershed Management Project (NEWMAP); Action Against Desertification etc have been initiated and implemented by government to counter food insufficiency. All of these efforts are aimed at increasing agricultural productivity in order to provide enough food to meet domestic demand as well as a plentiful supply of commodity crops for worldwide export.

\section{METHODOLOGY}

The study was based on the secondary data compiled from the various publication of NSSO (National Sample Survey Organization) of India, Indiastat and FAOstat. Similarly, data on Nigeria consumption were obtained from National bureau for statistics publications, Central Bank of Nigeria and FAO statistics. The time series data of 1950- 
2020 for population; and 1980-2018 were used for the study.

Demand and supply of major cereals were projected for the year 2030, 2040 and 2050 using different income growth scenarios; low, moderate and high GDP growth.

\section{Demand projections}

This study uses a simple growth rate model in estimating demand for cereals both in India and Nigeria. Demand projections in general are estimated on the basis of assumptions about the base year demand, population, expenditure elasticity and economic growth. The model was adopted and used by Dastagiri (2004) and stated as follows. Simple growth rate model:

Dt $=d_{0}^{*} N t(1+y * e) t$

Where,

Dt: is the household demand for a commodity in year $\mathrm{t}$;

do: is the per capita demand of the commodity in the base year;

$\mathrm{y}$ : is the growth in per capita income; e is the expenditure elasticity of demand for the commodity; and,

$\mathrm{Nt}$ : is the projected population in year $\mathrm{t}$.

\section{Supply projection}

Supply projections for major food commodities will be made using Box-Jenkins's forecasting Arima model (as employed by Mishra, et al., 2015) based on the methodology described in the classic work of Box and Jerkins. Uni-variate Arima models use only information contained in the series itself.
Thus, models are constructed as linear functions of past values of the series and/ or previous random shocks (errors). Forecasts will be generated under the assumptions that the past history could be translated into predictions for the future. ARIMA modelling will be developed the standard three steps procedures.

i) Identification of the model;

ii) Parameter identification and;

iii) Diagnostic and verification of the model.

The identification steps determine

a) whether the data is stationary and the possible transformations to obtain stationary and

b) whether the form of the data is autoregressive (AR), moving average (MA) or both (ARMA), and its orders.

Three parameters will be used in summarizing an ARIMA model and are the AR parameter $p$, integration parameter $\mathrm{d}$ and MA parameter $\mathrm{q}$. Parameters $p$ and $q$ denote the order of AR and MA, while $d$ denotes the degree of differencing the series to obtain stationarity. The autocorrelation function (ACF) and partial autocorrelation functions (PACF) of a series together are the most powerful too, usually applied to reveal the correct values of the parameters. The ACF gives the autocorrelations calculated at lags 1, 2 and so on; while PACF gives the corresponding partial autocorrelations, controlling the autocorrelations at intervening lags. Parameters estimation of tentative models will be determined maximumlikelihood methods. The autoregressive moving average (ARMA) model, denoted by $\operatorname{ARMA}(p, q)$, is given by

$$
Y_{t}=\Psi 1 Y_{t-1}+\Psi_{2} Y_{t-2}+\ldots \ldots \ldots+\Psi_{p} Y_{t-p}-\grave{\omega}_{1 z t-1}-\grave{\omega}_{2} \varepsilon_{t-2}-\ldots . .-\dot{\omega}_{q} \varepsilon_{t-q}+\varepsilon_{1}
$$

Or equivalently

$$
\Psi(B) y_{t}=\grave{\omega}(B) \varepsilon_{1}
$$

Where $\mathrm{B}$ is the backshift operator defined by

$$
B y_{t}=y_{t-1}
$$


A generalization of ARMA models which incorporates a wide class of non-stationary timeseries is obtained by introducing 'differencing' into the model. The simplest example of a non- stationary process which reduces to a stationary one after differencing is 'Random walk'. A process $\left\{y_{t}\right\}$ is said to follow autoregressive moving average (ARIMA), denoted by ARIMA

\section{$(p, d, q)$, if $\tilde{V}^{d} y_{t}=(1-B)^{d} y_{t} \varepsilon_{1}$ is $\operatorname{ARMA}(p, q)$.}

The model is written as

$$
\Psi(B)(1-B)_{d} y t=w(B) \varepsilon_{1}
$$

Where $\boldsymbol{\varepsilon}_{\mathbf{1}}$ are identical and independently distributed as $\mathbf{N}\left(\mathbf{0}, \mathbf{\sigma}^{2}\right)$. The integration parameter $d$ is a nonnegative integer. When $d=0$, the ARIMA $(p, d, q)$ model reduces to $\operatorname{ARMA}(p, q)$ model.

\section{RESULTS AND DISCUSSIONS}

\section{Population of food commodities for India and Nigeria}

The two countries are considered among the most fast-growing population nations of Asia and Africa. India in the past two decades, the growth rate has been slowing down, from 2.1 per cent per annum during the 1980 s to 1.9 per cent in the 1990s and presently around 0.99 per cent.

Table 1: Projections of population (In Million)

\begin{tabular}{|l|l|l|}
\hline Years & India & Nigeria \\
\hline $\mathbf{2 0 2 0}$ & 1380.0 & 206.1 \\
\hline $\mathbf{2 0 3 0}$ & 1503.6 & 262.9 \\
\hline $\mathbf{2 0 4 0}$ & 1592.6 & 329.0 \\
\hline $\mathbf{2 0 5 0}$ & 1639.1 & 401.3 \\
\hline
\end{tabular}

Source: Faostat, 2015.

Nigeria on the other side, at present, population growth was increasing at the rate of 2.58 per cent. From Table 1 it is indicated that by the year 2050, population was projected to reach 1639.1 and
401.3 million in India and Nigeria from the present $1,380.0$ and 206.1 million respectively in the year 2020.

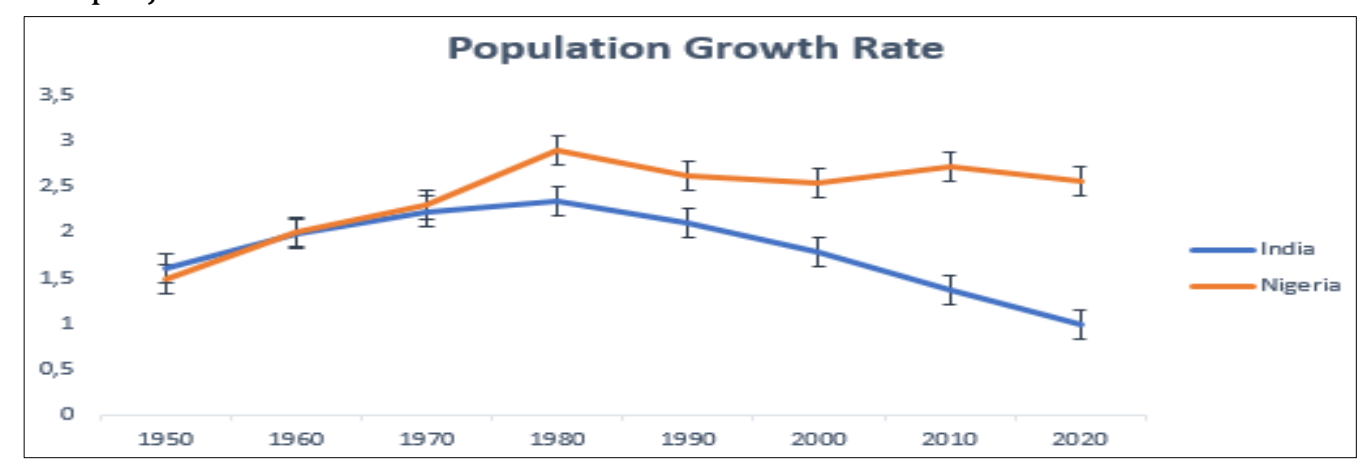

Source: Compiled from United Nations-World Population Prospects 


\section{Per Capita GDP Growth}

It was assumed that income growth rate was 6, 7 and 8 per cent for low growth, moderate and high growth scenario for both India and Nigeria. Furthermore, the adjusted per capita income of
India stands at 4.8, 5.8 and 6.8 per cent for the low, moderate and high growth scenario. Likewise for Nigeria, the adjusted per capita income was 3.4, 4.4 and 5.4 per cent for the low, moderate and high growth scenario for the study period.

Table 2: Alternative income growth rate assumptions used in demand projection (In Million)

\begin{tabular}{|l|l|l|l|l|}
\hline \multicolumn{2}{|l|}{} & \multicolumn{2}{|l|}{ Income } & \multicolumn{2}{l|}{ Per capita income } \\
\hline & India & Nigeria & India & Nigeria \\
\hline Low growth & 6 & 6 & 5 & 3.4 \\
\hline Moderate growth & 7 & 7 & 6 & 4.4 \\
\hline High growth & 8 & 8 & 7 & 5.4 \\
\hline
\end{tabular}

Population growth rate are $1.0 \%$ and $2.6 \%$ for India and Nigeria respectively under all income growth scenarios.

\section{Demand and Supply projection of food commodities for India and Nigeria}

Demand projection of various food commodities was computed using three different income growth scenarios of 6, 7 and 8 per cent GDP growth i.e., low, moderate and high growth for the years 2030, 2040 and 2050. The results for rice demand projection in the year 2030 would likely be observed between 106.57 and 106.8 million tonnes for the low- and high-income growth scenario, in 2040 rice would likely to reach 116.20 to 116.5 million tonnes for low and high growth income, and in the year 2050 rice demand likely to reach 122.6 to 122.4 million tonnes for low- and high-income growth scenario in India. (Compare with similar studies)

The wheat demand for the year 2030 was projected to be around 93.08 to 93.32 million tonnes, in 2040 it stands to be 98.08 and 98.09 million tonnes, in 2050 it was 105.03 to 105.05 million tonnes for the low- and high-income growth rate respectively. The demand projection results indicated almost similar growth rate pattern of 1.05, 1.04 and 1.06per centchange for the low-, moderate- and high-income growth. However, in a related study conducted by Kumar 1998 reported a demand for wheat for the year 2020 as $104.8,102.8$ and 100.3 million tonnes under the assumptions of 4, 5 and 7 per cent of income growth.
The demand for maize in India for the year 2030 was projected at 9.70 to 9.74 million tonnes, in 2040 it was projected at 10.55 to 10.59 million tonnes and 11.54 to 11.61 million tonnes for the year 2050 under the assumptions of low- and highincome growth. It was observed that there is a close similarity in the demand of maize across the three-income growth scenario. This was further buttressed from the demand growth rate observed as $1.05,1.05$ and 1.08 percentage changes in the demand of maize for the low-, moderate- and highincome growth. Therefore, demand for maize under different income growth of 6, 7 and 8 per cent would remain similar among it is consumers in India. That means change in income may have a little influence on the demand for maize. Clearly indicating that, while the aggregate food consumption increases less proportional with income, the consumption of some specific items may increase. These items, whose consumption increases more than proportionally with income, are often called 'luxuries' in the economic literature in contraposition to 'necessities'. While the consumption of starchy staples increases less than proportionally with food expenditure, the aggregate consumption of other food item must increase. 
Table 3: Demand projections for food commodities in India in different years in India (Low-income growth)

\begin{tabular}{|c|c|c|c|c|c|}
\hline \multirow{2}{*}{$\begin{array}{l}\text { Food commodity } \\
\text { India }\end{array}$} & \multicolumn{5}{|l|}{ Years } \\
\hline & 2013 & 2030 & 2040 & 2050 & Growth rate \\
\hline Rice & 89.26 & 106.5 & 116.5 & 122.6 & 1.05 \\
\hline Wheat & 77.96 & 93.08 & 98.08 & 105.03 & 1.05 \\
\hline Maize & 8.12 & 9.70 & 10.55 & 11.54 & 1.05 \\
\hline Sorghum & 4.58 & 5.47 & 5.98 & 6.48 & 1.05 \\
\hline \multicolumn{6}{|l|}{ Nigeria } \\
\hline Rice & 5.07 & 7.503 & 9.095 & 10.687 & 2.33 \\
\hline Wheat & 3.72 & 5.517 & 6.687 & 7.857 & 2.34 \\
\hline Maize & 5.82 & 8.61 & 10.44 & 12.27 & 2.33 \\
\hline Sorghum & 5.45 & 8.07 & 9.78 & 11.50 & 2.33 \\
\hline
\end{tabular}

- $\quad$ Note: The units in million tons for all commodities

- 2013 is considered as base

Furthermore, demand for sorghum for year 2030, 2040 and 2050 was projected at 5.48, 5.98 and 6.50 million tonnes across the entire three income growth scenario. Likewise, the growth rate for the demand of sorghum as food in India between the years 2013 to 2050 was observed to be in a similar trend of 1.05 percent across the entire three income growth: low-, moderate- and high-income growth. This fashion indicates that sorghum demand for food may not likely be increase with the increase in income among consumers. According to Parthasarathy 2010, reported his study findings that, while food use of sorghum has declined sharply at the all-India level, its use as food is still important in major producing states after rice and wheat although at levels 50per cent below that in 1972-73. The decline in per capita food consumption of Sorghum however seems to be plateauing at this lower level as indicated by data between 1999 and 2005. At the same time, the use of sorghum in alternative uses has increased from about 5per cent since 1993-94 to 30per cent or more between 1999 and 2005 .

Table 4: Demand projections cereals for different years in India and Nigeria (High income growth)

\begin{tabular}{|c|c|c|c|c|c|}
\hline Food commodity & Years & & & & \\
\hline India & 2013 & 2030 & 2040 & 2050 & Growth rate \\
\hline Rice & 89.26 & 106.8 & 116.5 & 122.4 & 1.06 \\
\hline Wheat & 77.96 & 93.32 & 98.09 & 105.05 & 1.06 \\
\hline Maize & 8.12 & 9.74 & 10.59 & 11.61 & 1.08 \\
\hline Sorghum & 4.58 & 5.48 & 5.99 & 6.50 & 1.06 \\
\hline \multicolumn{6}{|l|}{ Nigeria } \\
\hline Rice & 5.07 & 7.601 & 9.20 & 10.70 & 2.37 \\
\hline Wheat & 3.72 & 5.561 & 6.701 & 7.910 & 2.37 \\
\hline Maize & 5.82 & 8.670 & 10.60 & 12.31 & 2.34 \\
\hline Sorghum & 5.45 & 8.130 & 9.82 & 11.62 & 2.35 \\
\hline
\end{tabular}

- Note: The units in million tons for all commodities

- 2013 is considered as base 


\section{Demand projection of food commodities in Nigeria}

Demand projection of various food commodities in Nigeria was computed using a simple growth model for three different income growth scenarios of 6, 7 and 8 per cent GDP growth i.e., low, moderate and high growth for the years 2030, 2040 and 2050. The results for rice demand were projected for the year 2030 to likely be observed within7.601 and 7.601 million tonnes for the lowand high-income growth scenario, in 2040 rice would likely reach 9.095 to 9.201 million tonnes for low and high growth income, and in the year 2050 rice demand would likely reach 10.687 to 10.701 million tonnes for low- and high-income growth scenario in Nigeria. The growth rate of rice demand was 2.33, 2.35 and 2.37 per cent for the low-, moderate- and high-income growth scenario which was indicating a relatively similar growth in the demand of rice across the three-income scenario. By the way, indicating that there would not be any significant increase in the demand of rice due to relative change in income in Nigeria. Therefore, demand of rice was somewhat similar under the assumptions of 6,7 and 8 per cent GDP growth scenario. This is a common trend nature among cereals food commodities.

The wheat demand for the year 2030 was projected to be around 5.561 to 5.570 million tonnes, in 2040 it stands to be 6.687 to 6.701 million tonnes, in 2050 it would be 7.857 to 7.910 million tonnes for the low- and high-income growth rate, respectively. The demand projection results indicated almost similar growth rate pattern of 2.33, 2.34 and 2.37 per cent change for the low-, moderate- and high-income growth. It is clear that there was no significant difference in the demand for wheat across the three different income growth scenarios in Nigeria. This means increase in income may not influence any significant increase in the demand of wheat.

Moreover, demand for maize in Nigeria for the year 2030 was projected at 8.61 to 8.67 million tonnes, in 2040 it was projected at 10.44 to 10.60 million tonnes and 12.27 to 12.31 million tonnes for the year 2050 under the assumptions of low- and high- income growth. It was observed that there werenot very many differences in the demand of maize across the three-income growth scenario. This was been further buttressed from the demand growth rate observed as 2.33, 2.34 and 2.34 per cent changes in the demand of maize for the low-, moderate- and high-income growth, respectively. Therefore, demand for maize under different income growth of 6, 7 and 8 per cent would remain relatively similar among it is consumers in Nigeria. That means, change in income may have a little influence on the demand for maize. It is clearly indicated, while in the aggregate the consumption of food increases less than proportional with income, the consumption of some specific items may increase. These items, whose consumption increases more than proportional with income, are often called 'luxuries' in the economic literature in contraposition to 'necessities'. While the consumption of starchy staples increases less than proportional with food expenditure, the aggregate consumption of other food item must increase.

Nevertheless, demand for sorghum for year 2030, 2040 and 2050 was projected at about 8.13, 9.82 and 11.62 million tonnes across the threeincome growth scenario. Likewise, the growth rate for the demand of sorghum as food in Nigeria,within the years 2013 to 2050 was observed to be in a similar trend of about 2.35 percent across the entire three income growth;low-, moderate- and high-income growth rates. Meaning like other cereals category the relative increase in income may not influence any significant increase in the demand for sorghum in Nigeria.

\section{Supply projection of food commodities for India}

The projections of production (supply) as well as domestic consumption (demand) into future will be required by the policy maker in understanding and putting the necessary food policies in the right directions to forestall any envisage food shortfall in both the two countries.The futuristic supply projections for 2030, 2040 and 2050computed with Arima models were presented in Table 5. Rice domestic supply was projected to stand at about 
$120.50,129.70$ and 134.41 million tons for the year 2030, 2040 and 2050, respectively. From 2030 to 2050 rice supply projection would increase at a growth rate of 0.7 per cent. In a study conducted by Mittal 2008, the result of rice supply for the year 2021 and 2026 was 105.8 and 111.2 million tons with a growth rate of 0.9 per cent. This reveals that the rice supply growth rate was increasing at a very low pace in India, a trend which indicates the possibility that rice producers may be shifting away to the production of other crops that may promise better profits in future.

Wheat supply projection for the year 2030, 2040 and 2050 stands likely at 114.12, 123.59and 135.65 million tons with a growth rate of 1.6 per cent. The wheat growth rate appears to be more than that of rice growth rate, and if this trend should be maintained wheat may likely overtake the first position as the highest supplied cereals in the nearest future among other food crops in India. However, Mittal in 2008 projected the supply of wheat at a 91.6 and 97.9 million tons for the year 2021 and 2026 with a growth rate of 1.3 per cent respectively. This also confirms the findings of this study that suggest the growth rate of wheat is higher than that of rice and as well projecting good trends in the performance in future of wheat in India.

Likewise, maize supply was likely to reaches 25.67 , 29.39 and 33.01million tonnes in the year 2030, 2040 and 2050 respectively with a growth rate of 2.2 per cent. From the result in Table 5, maize appears to have the highest growth rate among all cereals and this trend is indicating an accelerative increasing supply of maize; as it is currently gaining ground into livestock feed industry in the country.It is production was growing faster than that of all other cereals, its growing demand as poultry feed, as well as for human consumptions due to changing food habits, the demand for food additives derived from maize and industrial consumption is also growing in India.

Table 5: Supply projections of cereals for different years in India and Nigeria

\begin{tabular}{|c|c|c|c|c|}
\hline Food commodity & Years & & & \\
\hline India & 2030 & 2040 & 2050 & Growth rate \\
\hline Rice & 120.50 & 129.70 & 134.41 & 0.70 \\
\hline Wheat & 114.12 & 123.59 & 135.65 & 1.60 \\
\hline Maize & 25.67 & 29.39 & 33.01 & 2.20 \\
\hline Sorghum & 6.07 & 8.08 & 10.03 & $\begin{array}{l}-7.78 \\
\end{array}$ \\
\hline \multicolumn{5}{|l|}{ Nigeria } \\
\hline Rice & 3.46 & 4.01 & 4.53 & 1.44 \\
\hline Wheat & 0.086 & 0.094 & 0.102 & 1.94 \\
\hline Maize & 7.91 & 8.33 & 8.94 & 0.66 \\
\hline Sorghum & 7.43 & 7.91 & 8.44 & 1.16 \\
\hline
\end{tabular}

The units in million tons for all commodities

Conversely, sorghum supply would likely reach a declining6.07, 8.08 and 10.03million tons for the years 2030, 2040 and 2050 respectively. Further, the growth rate of sorghum indicated a negative trend of -7.78 per cent, meaning that sorghum supply would be declining over the years and may likely continue to decline in the future. Parthasarath, 2010 in a study observed that a declining trend of sorghum in terms of alternative uses and available area for cultivations of sorghum. According to Carl et al., 2009 the sorghum story is complicated by a shift in production, from the rainy season (kharif) to the post rainy season (rabi). Changing consumption preference among consumers toward wheat and rice rather than coarse cereals reduced the demand of both rabi and karif sorghum, creating competition (especially for rainy season sorghum) from 
modern varieties of food as well as cash crops. Production declines in both seasons are evidently mainly driven by the reduction in area.

\section{Supply projection of food commodities for Nigeria}

The futuristic supply projections for 2030, 2040 and 2050 with Arima models were presented in Table 5. Rice domestic supply was projected to stand at about 3.46, 4.01 and 4.53million tons for the year 2030, 2040 and 2050 respectively. From 2030 to 2050 rice supply projection would be expected to increase at a growth rate of 1.44 per cent. This indicates a significant positive increase in the production of rice in Nigeria other things being equal. On a comparison, the growth rate of rice in Nigeria has surpassed that of India by almost double.

Wheat supply projection stands likely at 0.086 , 0.094 and 0.102 million tons year 2030, 2040 and 2050. The growth rate from 2030 to 2050 is expected to grow at 1.94 per cent. The wheat growth rate appears to be more than that of the rice growth rate although in absolute terms the projected rice supply quantity stands to be more than 40 times higher to wheat supply in Nigeria. Of course, consumption of wheat has increased over the years in Nigeria, with population growth. It has become one of the main diets in most homes and a major raw material for industry. But the challenge is inadequate supply (local production). Which can be attributed to lack of government's support, inability of local farmers to meet demand and millers' demand for imported higher grades.On a comparison, growth rate stands a bit higher than that of Indian wheat supply growth rates.

Additionally, maize supply would likely reach7.91, 8.33 and 8.94 million tons in the year 2030, 2040 and 2050 respectively with a growth rate of 0.66 per cent. From the result in Table 5, maize appears to have the lowest growth rate among rice and wheat. But even that, maize production would be considered to be the highest in terms of quantity among all the remaining cereals in Nigeria. This may be attributed to the fact that climate has favours the production of maize across different parts of Nigeria compared to other cereals coupled with its growing demand as poultry feed, as well as for human consumptions, the demand for food additives derived from maize and industrial consumption is also growing in Nigeria. However, in comparative terms, Indian maize supply growth rates appear to be the highest among all cereals of India, and stands more than tripled to that of Nigeria's maize which assumes the lowest among cereals crop with respect of supply growth rates.

More so, sorghum supply would likely to reaches $7.43,7.91$ and 8.44 million tons for the years 2030, 2040 and 2050 respectively. Interestingly, the growth rate of sorghum indicated a positive trend of 1.16 per cent meaning that sorghum supply would be expected to increases over the years unlike the declining trend observed in the supply of sorghum in India for the same period of time. This keeps Nigeria at an edge above India in the likely future production of sorghum.

\section{Demand - supply projection gap for food commodities in India.}

The base-line scenario in the year 2013 revealed that the production trends for all the commodities closely followed those for consumption. Interestingly, in 2030, across the three growth income scenarios, an average surplus production would likely to emerge for rice as 13.7 million tons, for wheat 20.8 million tons, maize 16.2 million tons, and an average deficit of 0.59 million tons of sorghum.

With this trend in demand - supplyprojection gap for the year 2030, it is clear that in terms of rice, wheat and maize,India would be not only selfsufficient, but would become surplus in these cereals, while on the contraryit would be in deficit of sorghum.

Subsequently, in the year 2040 under the threeincome growth scenario, an average surplus for rice would be 13.12 million tons, for wheat would be 25.5 million tons, maize 18.8 million, and a deficit of 2.09 million tons of sorghum. Interestingly, the result of the year 2040 indicated an improvement from the previous 2030 and 2040. During this same year, also, India would have a 
surplus of all the food commodities under study with the exceptions of sorghum. '

As the case may be, in the year 2050, a similar trend with the previous years was also been observed with rice which would be 12.01 million tons, wheat 30.6 million tons, maize 21.4 million tons, a deficit of 3.53 million of sorghum. Interestingly, the result of the year 2050 indicated an improvement from the previous 2040 where the surplus has increases significantly with percentage change of 16.6 per cent for wheat, 12.2 per cent for maize. Conversely, rice exhibited a declined surplus with about 9.3 per cent between the years 2040 to 2050. This kind of trend was only observed in rice where the surplus quantity declines in 2050 whereas other cereals indicated an increment in the surplus quantities from 2040 to 2050 with the exceptions of sorghum which remained a deficit.

In addition, the deficit in sorghum from the year 2040 to 2050 would be expected to increase further there by widening the deficit quantity with about 40.9 per cent.

Table 6: Demand - Supply gap of cereals for different years in India and Nigeria

\begin{tabular}{|c|c|c|c|}
\hline Cereals & Years & & \\
\hline India & 2030 & 2040 & 2050 \\
\hline $\begin{array}{ll}\text { Rice } & \text { (Surplus) }\end{array}$ & 13.70 & 13.20 & 12.01 \\
\hline Wheat (Surplus) & 20.80 & 25.50 & 30.6 \\
\hline $\begin{array}{ll}\text { Maize } & \text { (Surplus) }\end{array}$ & 16.20 & 18.80 & 21.4 \\
\hline Sorghum (Deficit) & 0.59 & 2.09 & 3.53 \\
\hline \multicolumn{4}{|l|}{ Nigeria } \\
\hline (Deficit) & 4.141 & 5.19 & 6.17 \\
\hline Wheat (Deficit) & 5.475 & 6.607 & 7.808 \\
\hline $\begin{array}{ll}\text { Maize } & \text { (Deficit) }\end{array}$ & 0.76 & 2.27 & 3.37 \\
\hline Sorghum (Deficit) & 0.7 & 1.91 & 3.18 \\
\hline
\end{tabular}

- The units in million tons for all commodities

\section{Demand - Supply projection gap for food commodities in Nigeria}

It is believed that the findings showcase what wouldoccur in the nearest future either food surplus or deficit and at large its implication on food security situations of the country. Interesting to start with, in the year 2030, across the three growth income scenarios, an average deficit in domestic supply would likely reaches 4.141 million tons of rice, a deficit of 5.475 million tons of wheat, a deficit of 0.76 million tons of maize, a deficit of 0.7 million tons of sorghum in Nigeria. Indicating that, by the year 2030 Nigeria would be staggering with huge food deficit in rice, wheat, and a marginal deficit in maize and sorghum domestic supply. This finding is in line with Ojoehemonet al., (2009), who noted that both rice production and consumption have vastly increased with rice demand outstripping rice production. Oyinbo, et al., 2013 reported that the rice demand-supply gap scenario has been an existing trend that would continue if appropriate measures are not taken.

Subsequently, in the year 2040 under the three income growth assumption scenarios, an average deficit of rice would be 5.190 million tons, deficit of wheat would be 6.607 million tons, deficit of 2.270million tons of maize, with a deficit of 1.910 million tons of sorghum, respectively.

As the case may be, in the year 2050, a similar occurrence with that of the previous 2040 scenario will be witnessed; with rice deficit standing at 6.170 million tons, wheat deficit of 7.808 million tons, maize deficit of 3.370 million tons and a deficit of 3.180 million tons of sorghum, respectively. 


\section{CONCLUSION AND RECOMMENDATIONS}

It is an irrefutable factual that India and Nigeria harbor significant percentage of food insecure people, no doubt. The findings reveal that in both the two countries demand for cereals food items virtually remain same in an event of relative change in income. Indicating that even when there is an increase in income among consumers the demand for cereals would not increase.Future supply growth rates favor maize with higher percentage compared to other cereals, with sorghum having the worst of all in India. In Nigeria alike, wheat had the highest supply growth rate with sorghum as the lowest. Altogether, Nigeria recorded higher supply growth rates than India with respectof rice, wheat and sorghum; on the contrary India has the higher supply growth rate in maize compared to Nigeria.

Interestingly to conclude, in the years 2030, 2040 and 2050 India would not only be self-sufficient on rice, wheat and maize but would become surplus nation, as all the projected production figures are more than consumption figures except for sorghum. The expected production for rice, wheat and maize would exceed the corresponding consumption demands. Therefore, with this trend it will be fair to deduce that India would be satisfying one of the most important dimension of food security aspect i.e. food availability by maintaining self-sufficiency of basic food commodities with deficit challenges in sorghum.
Nigeria conversely, would be staggering with a huge deficit in rice and wheat, a marginal deficit in maize and sorghum for the year 2030. In the subsequent 2040 and 2050 however, the country would plunge into a serious huge deficit on all cereal food.

It is in this regard, that, India must strengthen effort in maintaining this position of sufficiency while adopting new strategies to expand the production and productivity of sorghum through the use of high yielding varieties, input and credit support. On the other hand, need to focus more on making sure that cereals be made more available, accessible at affordable price to the teaming food unsecure as self-sufficiency alone doesn't in anyway represent a country is food secured.

The case of Nigeria is more alarming and pathetic; the envisaged huge deficit would profoundly impact in deteriorating the food insecurity situation of the country farther. As a matter of seriousness, government and other stakeholders must collaborate to declare agricultural sector under a 'state of emergency' through public investment in irrigation, credit facilities, research, extension and modern technology with the aim of expanding its local production there by reducing the over dependence on importation and improving food security of the country. 


\section{REFERENCES}

Anand, R., Kumar, N. and Tulin, V.(2016).Understanding India's food inflation: the role of demand and supply factors. IMF Working Paper Asia and Pacific Department WP/16/2.

Anon, D.(2003).Nutrition and the prevention of chronic diseases. In WHO Technical Report Series, Geneva, 916, 1-150

Anonymous (2021a). Nigeria Agriculture. Retrieved from

https://www.nationsencyclopedia.com/ec onomies/Africa/Nigeria-AGRICULTURE.html

Anonymous (2021b).Nigeria Agribusiness current state. Retrieved from https://www.pwc.com/ng/en/assets/pdf/ afcfta-agribusiness-current-state-nigeriaagriculture-sector.pdf

Atinmo, T. and Adeniran, T.(1999).Policy failure in the search for food security in Nigeria. In: Ogunrinade, A., Oniangio, R. and May, J. (eds), Not by bread alone: food security and governance in Africa, South Africa, Toda. Institute for Global Peace and Policy Research.

Carl, E. and Latha, N.(2009).Pearl millet and sorghum improvement in India. IFPRI Discussion Paper 00919. Pp8-10

FGN/ WHO(2004). Millennium Development Goals Report. Abuja: FGN/WHO.

Food and Agricultural Organisation(FAO)(2014).FAO Statistical Data Base. Retrieved http://apps.fao.org.

Gahukar, R.T.(2011).Food security in India: The challenge of food production and distribution. Journal of Agricultural and Food Information, 12: 271.

Goyal, S.K. and Singh J.P.(2001).Demand versus supply of food grains in India: Implications to food security. Paper at the $13^{\text {th }}$ International IFMA Congress of Farm Management on Feed the
World-Please the Consumer-Maintain the Environment held at Wageningen, The Netherlands.

Hussain, A.O. and Sulaimon, H.O.(2018).A comparative study of food security in Africa amid growing population. International Journal of Scientific and Research Publications, 8(10): $\quad$ 2-8

Isah, M. A., Samuel, E., Makama, S.A. and Kiresur, V.R.(2015).Trend of area, Production and Productivity of major cereals: India and Nigeria Scenario. Research Journal of Agriculture and Forestry Science, 3(2):10-15.

Joseph, M.A.(2011).Major cereal grains production and use around the World. ACS Symposium Series, American Chemical Society: Washington, DC, 1-8

Kirit, S.P.(1998).Food Security: Individual and National-In India's Economic Reforms and Development: Essays for Manmohan Singh. Isher Judge Ahluwalia and I.M.D (eds.). Little (New York, NY: Oxfod University Press, 1998), 253.

Kumar, P., Joshi, P.K. and Mittal, S.(2016).Demand vs supply of food in India - futuristic projection.

Proceeding of Indian National Science Academy, 82 No. 5. Pp. 1579-1586

Madhura, S.(2010).Population and Food Security. In: A.K. Shiva Kumar, Pradeep Panda, and Rajani R. V (eds.), Handbook of Population and Development. New York, NY: Oxford University Press, Pp. 53.

Ojehomon, V.E.T., Adebayo, S.B., Ogundele, O.O., Okoruwa, V.O., Ajayi, O., Diagne, A. and Ogunlana, 0. (2009). Rice Data Systems in Nigeria: National Rice Survey.

Parthasarathy, R.P., Basavaraj, G., Ahmad, W. and Bhagavatula, S.(2010).An analysis of availability and utilization of sorghum grain in India. Journal of SAT Agricultural Research, 8:1-7

United Nations - World Population Prospects (2021). Retrieved from https://www.macrotrends.net/countries/IND/in dia/population-growth-rate 